\title{
Design and Analysis of Planar Transformers in Modern Switching Mode Power Supply
}

\author{
Islam Hassan ${ }^{\mathrm{a}^{*}}$, Khairy Sayed $^{\mathrm{b}}$ \\ ${ }^{a}$ ITEC-Assiut, Egypt \\ ${ }^{b}$ Electrical Engineering Department, Sohag University, 82524, Sohag, Egypt
}

\begin{abstract}
This paper presents a development and calculated rating of high-frequency transformer connect with switch-mode power supplies. These power supplies are used in various devices such as power personal communications services, television, DVD players and charge mobile phones Thus, increasing power density and decreasing cost are still the main factors in designing a switch-mode power supply. Magnetic elements represent a great amount of size in switch-mode power supplies and therefore volume reduction and power density raise are beneficial. These switch-mode power supplies consist of two power stages separated by a power transformer with high frequency power. The transformer architecture, which can run at a high frequency, has since become a major challenge for the engineers. Lower component height and better thermal management are advantages with the planar core design. This paper provides a detailed summary of the operating principles of high-frequency transformers. Two transformers are compared in a dual active bridge converter: a wire wound, a planar. This paper discusses a comparison between the wire-wound transformer, high-frequency transformer, and structures in terms of winding loss, core loss, leakage inductance, parasitic capacitance the focus of this research is to find an optimal transform solution for the converter operating at a power level of $220 \mathrm{~W}$. Furthermore, the power losses of a planar transformer are estimated.
\end{abstract}

(C) 2021 Published by Published by Faculty of Engineering - Sohag University. DOI: 10.21608/SEJ.2021.94318.1003

Keywords: Planar transformer, switch mode power supply, DC-DC power converter, dual active bridge, high-frequency transformer, phaseshift.

\section{INTRODUCTION}

Power transformers have a 19th century past when Faraday introduced the concept of electromagnetic induction. Starting in the 1960s, the frequency of switch-mode power supply had a direction to rise. In a switchedmode power supply, they are generally regarded as the bulkiest and most expensive components [1]. They are also critical for the performance of power converters: dynamic response, efficiency, multiple secondary, and electromagnetic interference cross-regulations. So many research institutions and organizations tried to invent power converters that could work at a frequency above 20kHZ. The high-frequency operation has the advantages of reducing the size of the element in the power converters, low weight, low cost, and high performance [2]. This direction led to the development of various topologies for high-frequency power converters such as resonant converters and the dual active bridge (DAB) converter. Such converters comprise two power phases separated by a power transformer with high frequencies. This transformer model, which can operate at a high frequency, has since become a major challenge for the engineers. This is because as the size of the components decreases, parasitic parameters such as leakage inductance, parasitic capacitance, and ac resistance begin to influence the adapter output in a significant way.

With Planar technology, the planar printed circuit board (PCB) magnetics benefit from using printed circuit board (PCB) tracks as windings, instead of structuring magnetic parts like transformers and inductors of wirewound assemblies on bobbins. The benefits are assembly facilitation and no longer the prerequisite of the magnetic screening tests. This is a section about cost reduction implemented. It gives a detailed study effect of the distribution of the magnetic field, loss of the eddy currents. Compare the scale, losses, and high-frequency costs of two different types of transformers.

In recent years high-frequency transformer-isolated DC-DC power converters have been effectively implemented as a switched-mode power conditioner in many applications. Several new techniques for high-

${ }^{*}$ Corresponding author: islamali2210@gmail.com. 
frequency DC-DC converters have been proposed to reduce the voltage and current peak stresses and surges, switching losses while achieving high power density and improved performance [3]. It consists of Two $\mathrm{H}$ Bridges with their AC terminals connected to the primary and secondary windings of a high-frequency transformer. The operational principle of the DAB is based on phase shift control: the outputs of two voltage bridges are phaseshifted from each other by the phase shift (PS) angle $\phi$. Then, by changing the angle, the amount of power transferred between two bridges can be controlled. It has some advantages as constant switching frequency control, lower switching power losses, quick transient response, reduced EMI and RFI, and lowered high frequency ringing current as well as due to their ability to increase the operation frequency [4]- [9]. Typical phaseshift (PS) PWM soft-switching DC-DC power converter using high frequency planar transformer (HFPT) is shown in Fig. 1. This power converter consists of an H-voltage source type FB inverter that includes four MOSFET switches $Q 1 \sim Q 4$ switches with built-in anti-parallel diodes in the primary high-frequency transformers. With its magnetizing inductance, leakage inductance, and high-frequency ideal transformer, this transformer is modelled and connected across the high-frequency inverter. An effective rectification chain, including two D5D6 diodes, is provided in the secondary-side. The transformer leakage $\left(L_{K}\right)$ and magnetizing inductance $\left(L_{m}\right)$ are in turn used as a mild quasi-resonant inducer aided by switching. The load is connected through a chock style LC filter $\left(L_{o}, C_{o}\right)$ across the secondary side.

High performance, small component size, low system stress and low switching losses, zero-voltage switching capacity, a small number of components, and bidirectional power flow are the major advantages of the DAB converter. DAB converters can be used in a range of applications including automotive, renewable energy, and smart grid. It is capable of stepping up or down the voltage by changing the transformer's turn's ratio. DAB converters reduce the number of components because there is no need for output inductor filters [10-14]. A Highfrequency transformer provides galvanic insulation. Additionally, high power densities can be achieved with high efficiency. On the contrary, the drawbacks of DAB converter are the presence of high circulating current in the transformer, which increases losses and not being able to take advantage of the zero-voltage secondary (ZVS) feature at light loads [15]- [16]. The key component of the DAB is the high-frequency transformer whose internal leakage inductance (Lk) can be used as the main component for transferring energy; therefore, it is a crucial factor in designing the transformer. Leakage inductance, therefore, determines the maximum transferable power for a given switching frequency. Zero-voltage switching can be achieved using the internal leakage inductance of the transformer [17] - [18]. Our goals in this paper are a comparison between the planar transformer and wire-wound transformer in winding loss and core loss. Determine the optimal transformer solution for the DAB application at a power level of $2 \mathrm{~kW}$. Some of the criteria are the size, low cost, high efficiency, and maintaining the appropriate levels of leakage inductance.

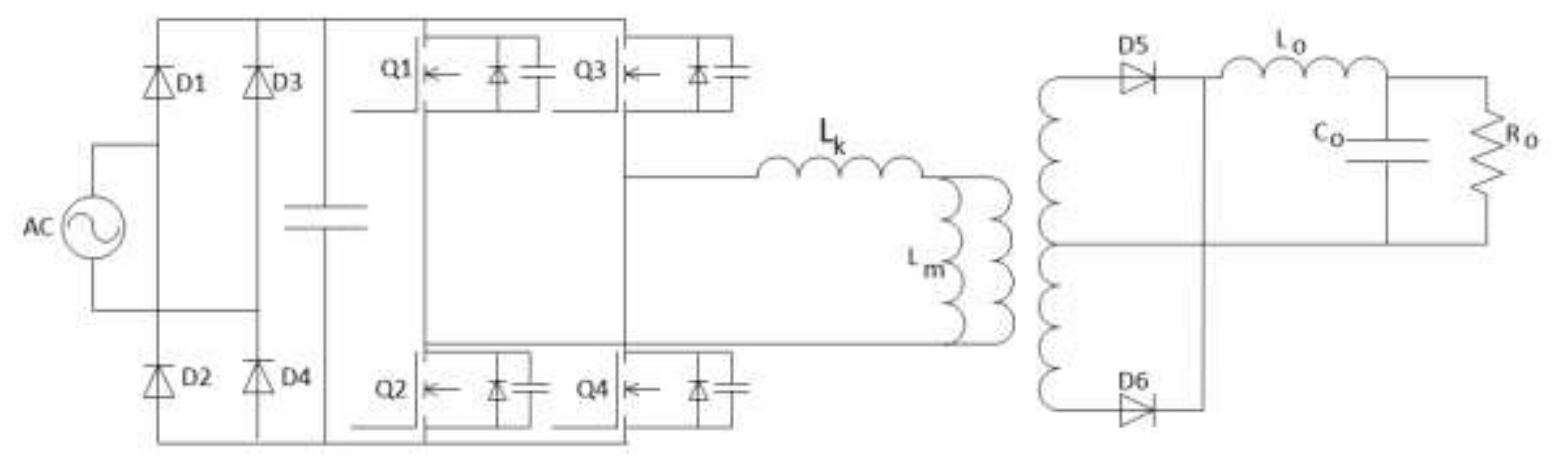

Fig.1. Phase-shifted soft switching PWM DC-DC converter using HFPT.

\section{PRINCIPLE OF OPERATION}

The planar transformer is where printed circuit boards (PCBs) replace the conventional wire windings. The operating frequency of these transformers is not constrained by skin effect because the conductors are thin copper foil. A planar transformer appears in Fig.2 However, the planar transformer also has many drawbacks such as cost, no maintenances (if destroyed, the entire power stage must be replaced), and limited range over which the inductance of the leakage can be regulated. 


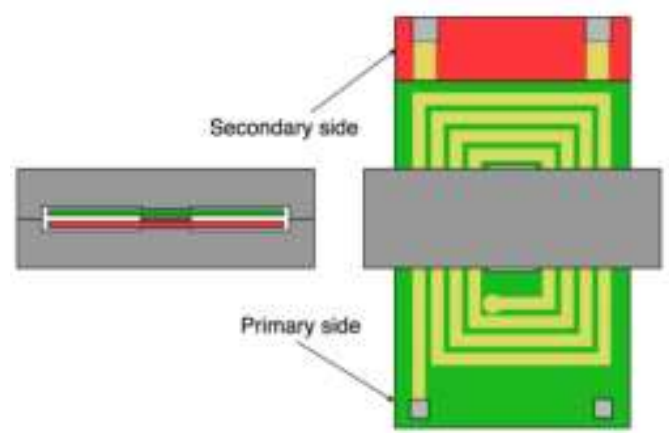

Fig. 2. Architecture of planar transformer.

The operating theory of the transformer is based on the Faraday Theorem, which states that the electromagnetic force $(v(t))$ produced in the circuit is equal to the negative amount of the time-varying magnetic flux (equivalent $(\mathrm{t})$ ) in the contour [19]:

$$
v(t)=-N \frac{d \Phi(t)}{d t}
$$

The transformer is an electrical mechanism that can be used to input (step-up or step-down transformers), current adjustments (current transformer), or galvanic separation between two parts of the circuit to increase or decrease the output voltage. The transformer typically consists of the magnetic core, which can be made of various materials (ferrite, electric steel) and which have different shapes (EI, EE, UU, UI, Planar core, etc.) and two or more windings, generally made of copper. The current $I p$ which flows through the primary winding generates the core magnetic flux. The flux lines that pass through the magnetic core induce voltage $V s(t)$ in the transformer's secondary winding, as shown in Fig.3. The load connected to the secondary side induces the flow of the current Is through the circuit. Then the power is transferred in transformers without any physical contact between the conductors.

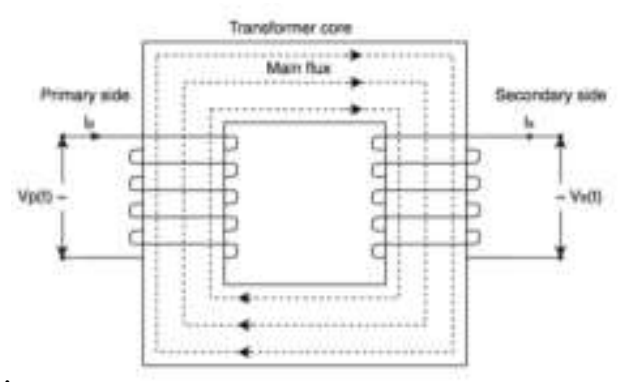

Fig. 3. The flux paths of the transformer.

Another relevant rule on electromagnetism is the Rule of Ampere. Ampere 's Law is one of four Maxwell equations that explain the electromagnetism theory [20]. It states that the magnetic field generated by the closed conduction path is equal to the electrical current in this direction:

$$
\int H l * d l=\int J * d S
$$

where $H$ is the magnetic field and $J$ is the current density. If the current flows through the wounded wire on the magnetic core, then the law of Ampere is in the following form [10]:

$$
\int \vec{H} l * d l=\int J * d S S=N I
$$

where $N$ is the number of turns in the heart and $I$ is the current flowing through the wire. The $N I$ result is equivalent to magneto motive force $(M M F)$. Using the following equation to locate $M M F$ :

$$
M M F=N I=\Phi \mathcal{R}
$$

where $\Phi$ is the magnetic flux and $\Re$ is the reluctance of the core. The reluctance of the core is calculated as: 


$$
\mathcal{R}=\frac{l_{e}}{\mu A_{c}}
$$

Where $l_{e}$ is the transformer 's magnetic length direction, $\mu$ is the core material's permeability and $A_{c}$ is the cross sectional area of the core. After Fig.3, the transformer is just two winding ones. Applying the law of Ampere will result in the following expressions:

$$
\begin{aligned}
& M M F=N_{p} I_{p}+N_{s} I_{s} \\
& \Phi \mathcal{R}=N_{p} I_{p}+N_{s} I_{s}
\end{aligned}
$$

Magnetic circuits can be found as being similar to electrical circuits. For example, resistivity $(R)$ is the magnetic equivalent of the resistance, and the equivalent of the electrical current is magnetic flux (all). Planar transformer was discovered in the 1980's [21], and its popularity has risen significantly in recent years due to the many advantages of this system. The planar transformer is where printed circuit boards (PCBs) replace the conventional wire windings. The operating frequencies of these transformers are not constrained by skin effect because the conductors are thin copper foil.

\section{HIGH-FREQUENCY TRANSFORMERS DESIGN}

The aim of high frequency transformer design is to find optimum values of the DAB isolated DC-DC converter's leakage inductance, phase-shifted angle, core measurements, turn ratio, and winding information to reduce total converter losses (conduction and switching losses, winding losses, and core losses) and to compare this design with wound wire transformer. Usually, ferrite core should be chosen for high-switching frequency applications to reduce eddy current loss in the core [22]. The high frequency transformer (HFT) design specification is specified in Table 1 . The output voltage range from $90 \mathrm{~V}$ to $140 \mathrm{~V}$ refers to battery voltage variability when the converter is used as a bidirectional charger.

\begin{tabular}{ccc}
\hline \multicolumn{3}{c}{ TABLE 1. DESIGN SPECIFICATIONS AND CIRCUIT PARAMETERS. } \\
\hline Item & Symbol & Value \\
\hline Input voltage & $V_{\text {in }}$ & $220 \mathrm{~V}$ \\
\hline Output voltage & $V_{\text {out }}$ & $24 \mathrm{~V}$ \\
\hline Output current & $I_{\text {out }}$ & $12.5 \mathrm{~A}$ \\
\hline Frequency & $f$ & From $100 \mathrm{kHz}$ to $500 \mathrm{kHz}$ \\
\hline Flux density & $B_{m}$ & $0.2 \mathrm{~T}$ \\
\hline Core material & $C M$ & Ferrite \\
\hline Core configuration & $C C$ & Planar E, EE \\
\hline
\end{tabular}

When designing a high-frequency transformer, one of the key criteria for evaluating the capacity to handle power is the product area $\left(A_{p}\right)$ :

$$
A_{p}=\frac{P_{t} \times 10^{4}}{K_{f} \times B_{m} \times K_{u} \times f \times J}
$$

where $K_{f}$ is a coefficient of a waveform (equals 4 for square waveform and 4.44 for sinusoidal waveforms), $B_{m}$ is the core 's maximum flux density, $J$ is current density, and $K_{u}$ is a window utilization factor. The maximum density of the flux $B_{m}$ can be determined by [23], [24]:

$$
B_{m}=\left[10^{8} \times \frac{\lambda^{2} \rho I_{\text {total }}^{2} M L T}{2 K_{u} W_{a} A_{c}^{3} M P L \beta K_{f e}}\right]^{\frac{1}{\beta+2}}
$$

where $\rho$ is $1.724 \times 10^{-6}$ is the resistivity, $\lambda=D \times T \times V_{\text {in }}$ is applied volt, $D$ is the duty cycle, $T$ is the period, $I_{\text {total }}$ is the total current, $K_{u}$ is the winding fill factor, $\beta$ is the exponent of core loss, and $K_{f e}$ is the core loss coefficient. When you find $A_{p}$, you can pick the transformer core from the manufacturer's datasheet. Also, for 
further measurements, the following core parameters must be taken from the datasheet: mean length turn (MLT), core area $\left(A_{c}\right)$, window area $\left(W_{a}\right)$, surface area $\left(A_{t}\right)$, magnetic path length (MPL), and core mass. Since not all of the above parameters are included in the datasheet, they must be determined.

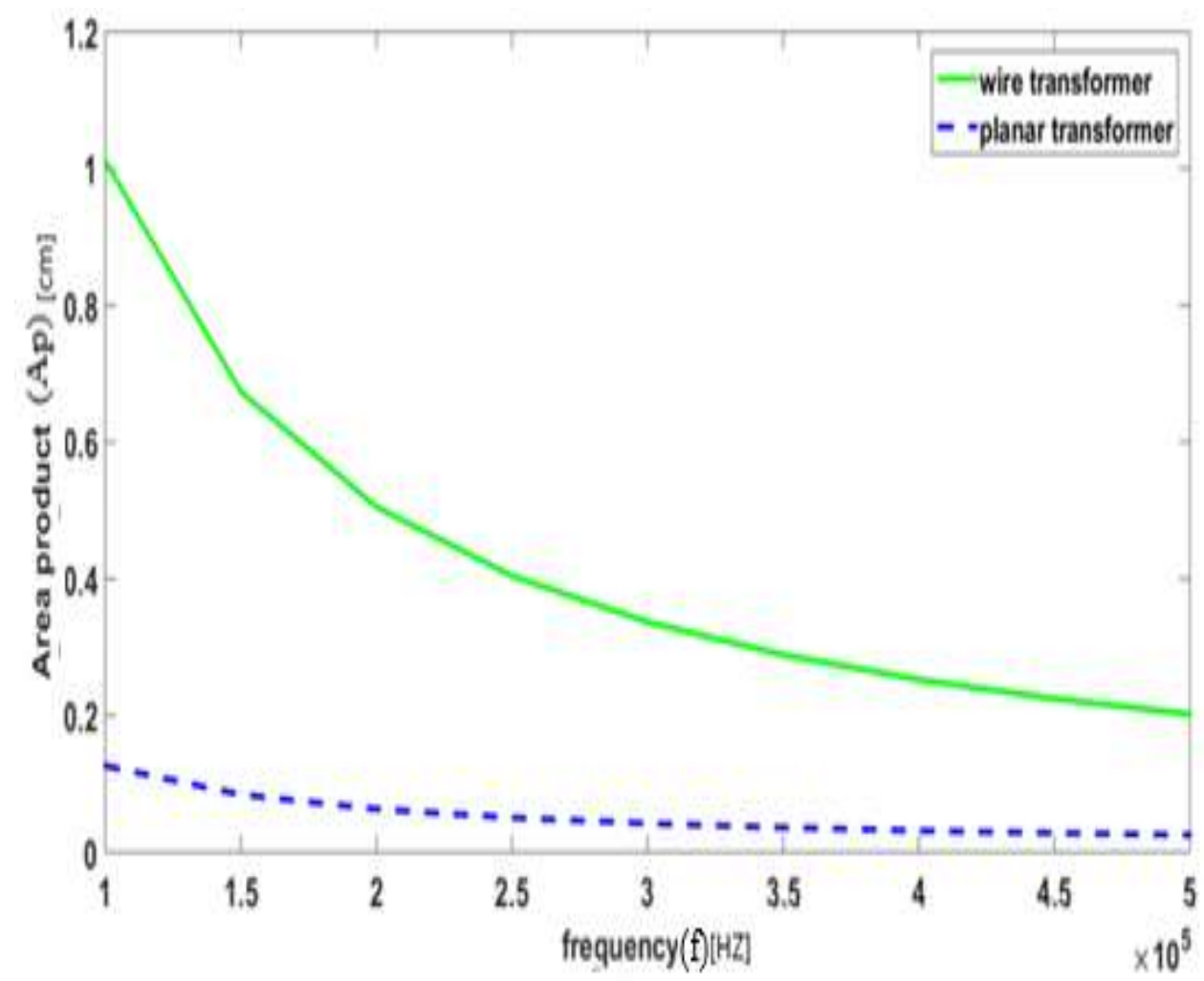

Fig.4 relationship between Area product with frequency in planar transformer and wire wound transformer.

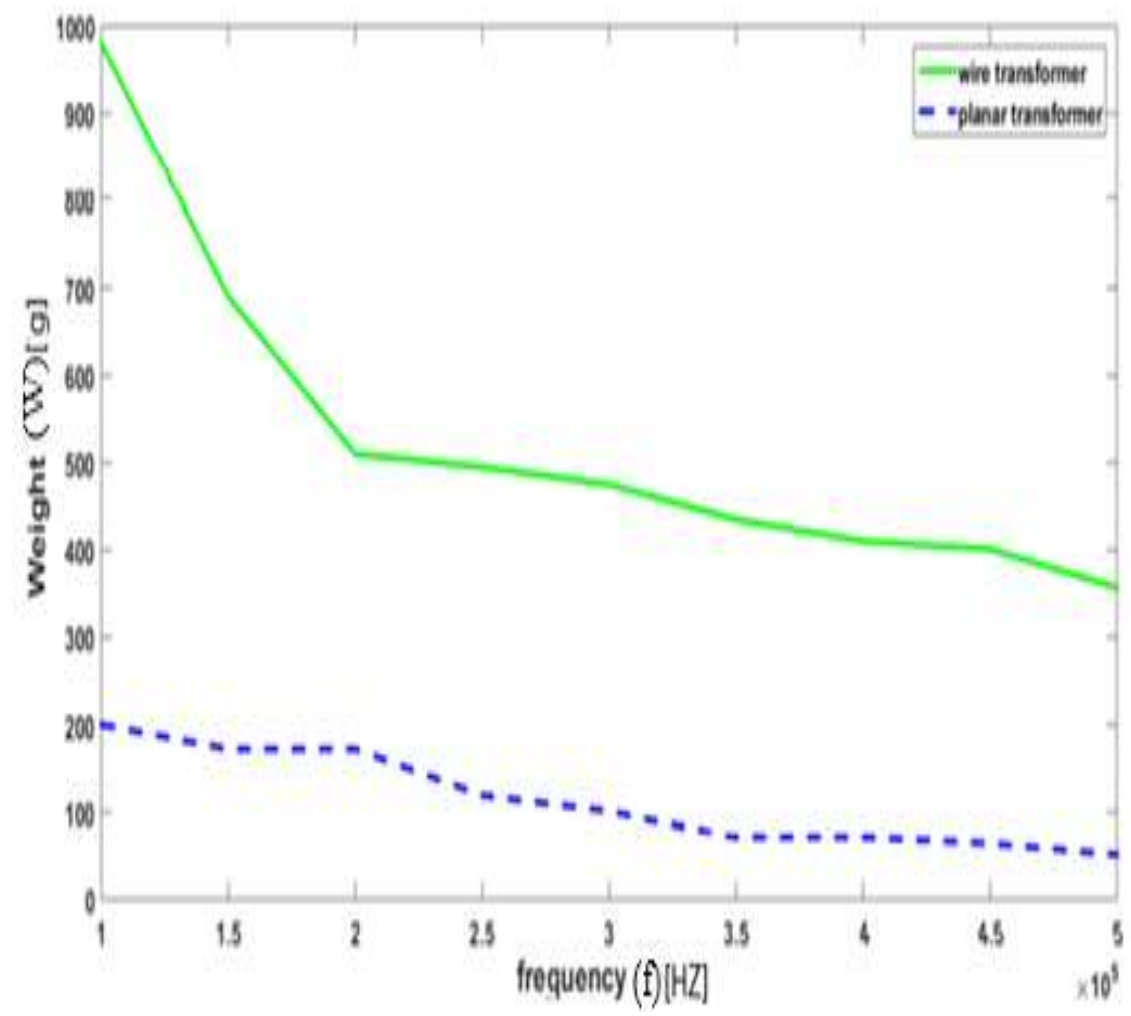

Fig.5 relationship between Weigth with frequency in planar transformer and wire wound transformer. 


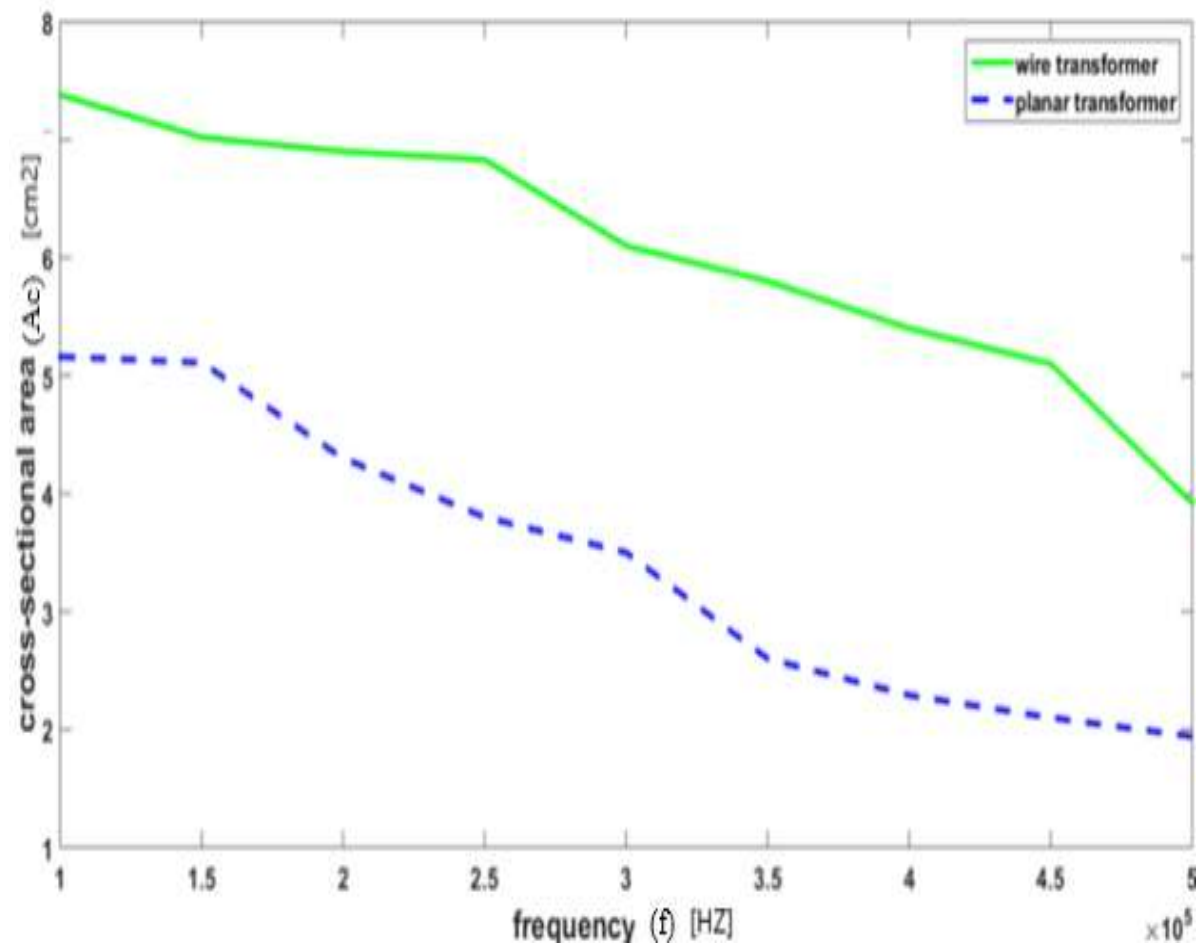

Fig.6 relationship between cross-section area with frequency in planar transformer and wire wound transformer.

From Fig. 4, we find that the area product $\left(A_{p}\right)$ in a planar transformer is less than the wire wound transformer with that frequency. By increasing frequency, the value of area product of planar and wire wound transformer is less. So, the weight of the planar transformer is lower from the core datasheet than the wire wound transformer shown in Fig. 3. Also, value of mean length turn (MLT) and value of surface area in planar transformer less than those value in wire-wound transformer because when the value of product area is low, the value of Dimensions of core is less. In Fig. 4 the central cross-sectional area $(A c)$ is one of the key parameters in the datasheet [25]. This is used to measure important parameters such as inductance leakage and inductance magnetization. This is used to measure important parameters such as inductance leakage and inductance magnetization. Use $\left(A_{c}\right)$ can also find the number of main $\left(N_{p}\right)$ and secondary $\left(N_{S}\right)$ turns:

$$
N_{p}=\frac{V_{i n} \times 10^{4}}{K_{f} \times B_{m} \times A_{c} \times f}
$$

where $N_{p}$ is the number of turns of primary, $V_{\mathrm{in}}$ is the input voltage, $K_{f}$ is the core loss coefficient, $B_{m}$ is flux density, $A_{c}$ is the cross-sectional area of the core, and $f$ is operating of frequency.

\section{LOSSES OF HIGH-FREQUENCY PLANAR TRANSFORMER}

The final stage of the design is the determination of the loss existing in the transformer. The loss of the transformer is another major concern in high-frequency power devices as they can reduce the overall performance. Consequently, the loss issue allows designers to be very careful when selecting the transformer's magnetic cores and winding. The amount of power transmitted in an ideal transformer is limited only by the saturation flux of the magnetic core and the flux limit. The loss of the transformer can be split into two categories: centre loss and winding loss (copper).

The main advantage of high-frequency operation is that the magnetic components are reduced in bulk. Comprehensive analysis of the centre and winding losses is given in this document. The study provides a detailed explanation of how core and winding losses should be calculated. 


\subsection{Loss of magnetic core}

Losses of the magnetic core can usually be divided into three parts: current loss of eddy, loss of hysteresis, and loss of excess. The magnetic core losses per unit mass can be determined by [26], [30-35]:

$$
P_{c}=C_{h} B_{m}^{\alpha} f+C_{m} B_{m}^{2} f^{2}+C_{e x} B_{m}^{1.5} f^{1.5}
$$

where $C_{h}, C_{e}$, and $C_{e x}$ are the coefficients, respectively, of eddy current loss, hysteresis loss, and excess loss. $f$ is the high-frequency transformer operating frequency and $B_{m}$ is the core's average magnetic flux density. $\alpha$ is an undetermined index related to the given magnetic material. Another reduced method for estimating core losses is as follows [27], [36-37]:

$$
P_{c}=C_{w} k B_{m}^{\alpha} f^{\beta}
$$

where $C_{w}$ is the waveform dependent coefficients of Magnetic flux amplitude, sinusoidal wave 1 and square wave $p / 4$, and Triangle wave $2 / 3 . K, a$, and $b$ are coefficients which are provided by manufacturers directly which can also be found in the manufacturer's datasheets.

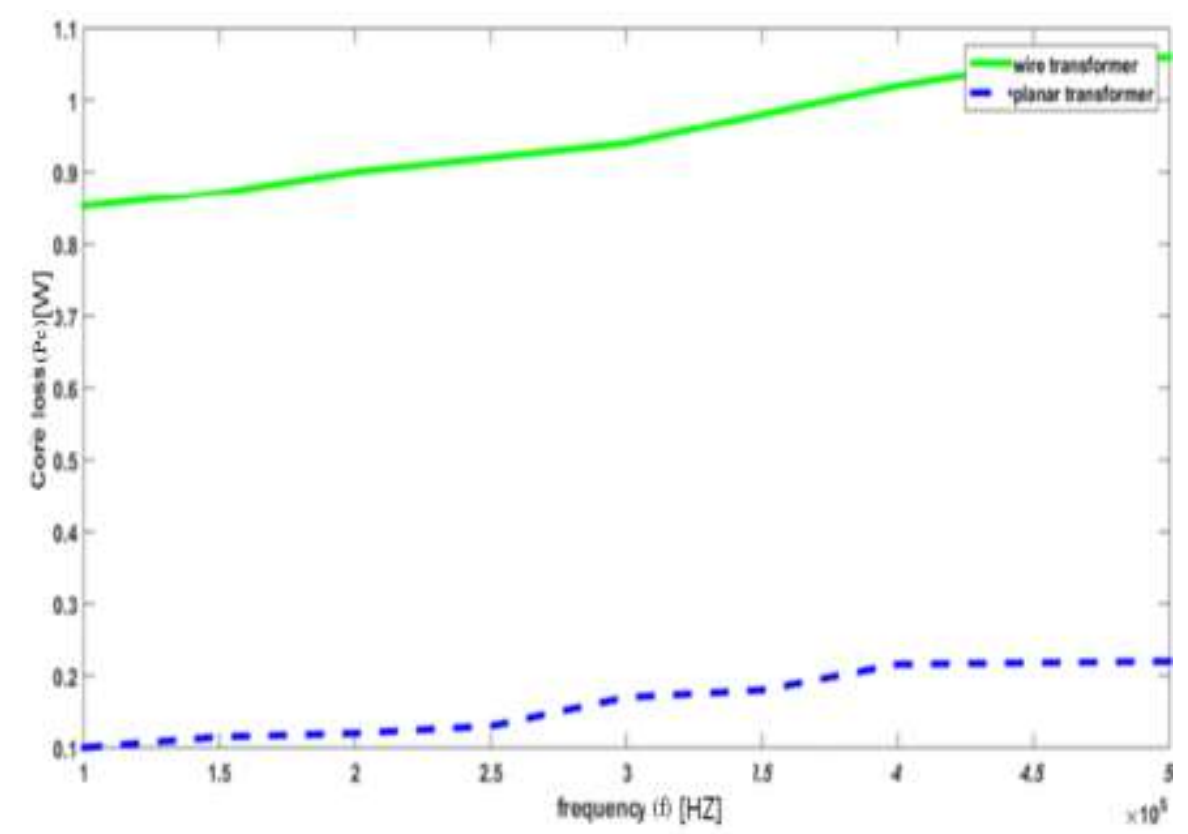

Fig.7 Relationship between core loss with frequency in planar transformer and wire wound transformer.

In Fig. 7, the loss of core in planar transformer is less than the loss of core in wire-wound transformer with increased frequency because dimension of core in planar transformer is less than dimension of core in wire-wound transformer. And by increasing value of frequency, the value of core loss is increased.

\subsection{Losses of the planar windings}

The loss of winding of the transformer can be calculated by:

$$
P_{w}=k_{r} R_{D C} I_{r m s}^{2}
$$

where $R_{D C}$ is the winding's direct current resistance, and $I_{\mathrm{rms}}$ is the mean root square. The $k_{r}$ is the alternative current resistance coefficient which can be expressed as follows [28], [38-40]:

$$
k_{r}(x . m)=x \times\left[\frac{\sinh (2 x)+\sin (2 x)}{\cosh (2 x)-\cos (2 x)}+\frac{2\left(m^{2}-1\right) \sinh (x)-\sin (x)}{3 \cosh (x)+\cos (x)}\right]
$$

where $\mathrm{m}$ is the number of layers of transformer winding, and $x=\frac{h_{c}}{0.071 \sqrt{f}}$ In which $h_{c}$ is the thickness of the conductor wires. 


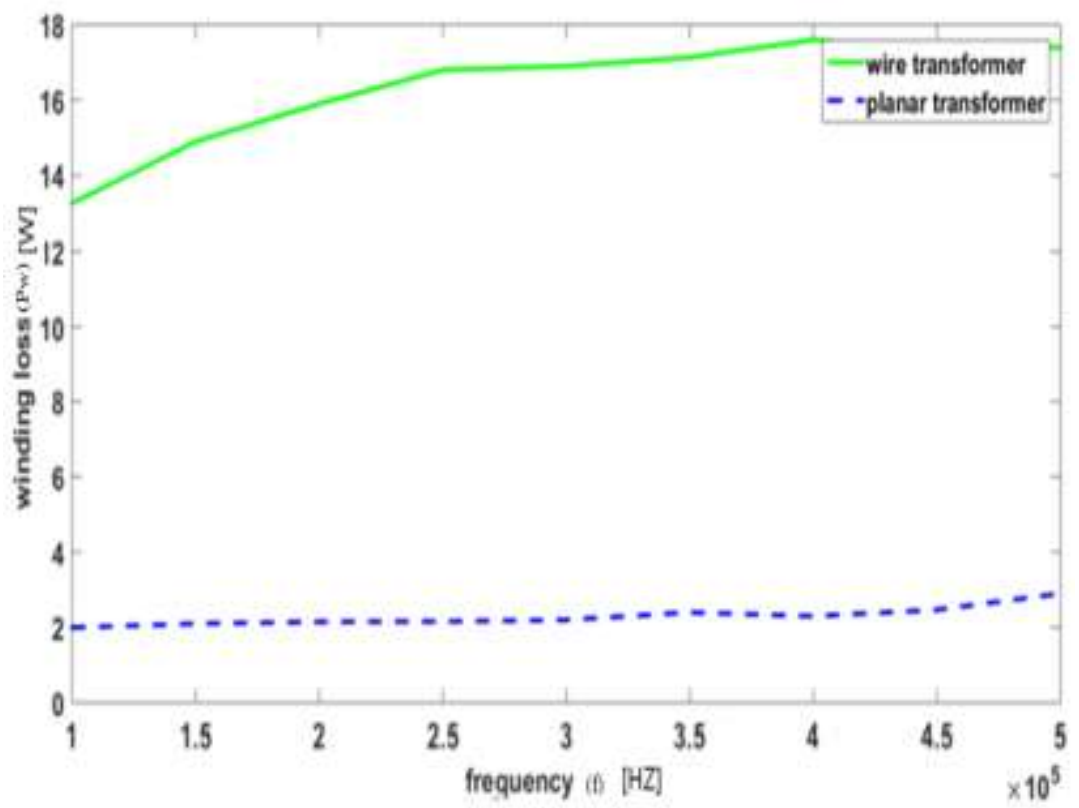

Fig. 8 relationship between winding loss with frequency in planar transformer and wire wound transformer.

In Fig. 8, the loss of winding in planar transformer is less than the loss of core in wire-wound transformer with increased frequency because PCB winding in planar transformer is instead of wires in wire-wound transformer. And by increasing value of frequency, the value of core is increased.

\subsection{Efficiency of high frequency transformer}

To reach the optimal of high frequency transformer, we should calculate the efficiency of high frequency transformer by

$$
\eta=\frac{P_{o}}{P_{o}+P_{\text {loss }}}
$$

where $\eta$ is efficiency of the high-frequency transformer, $P_{o}$ is output power of the high-frequency transformer, and $P_{\text {loss }}$ is total power loss in the high-frequency transformer which calculate from equations (12) \& (13):

$$
P_{\text {loss }}=P_{c}+P_{w}
$$

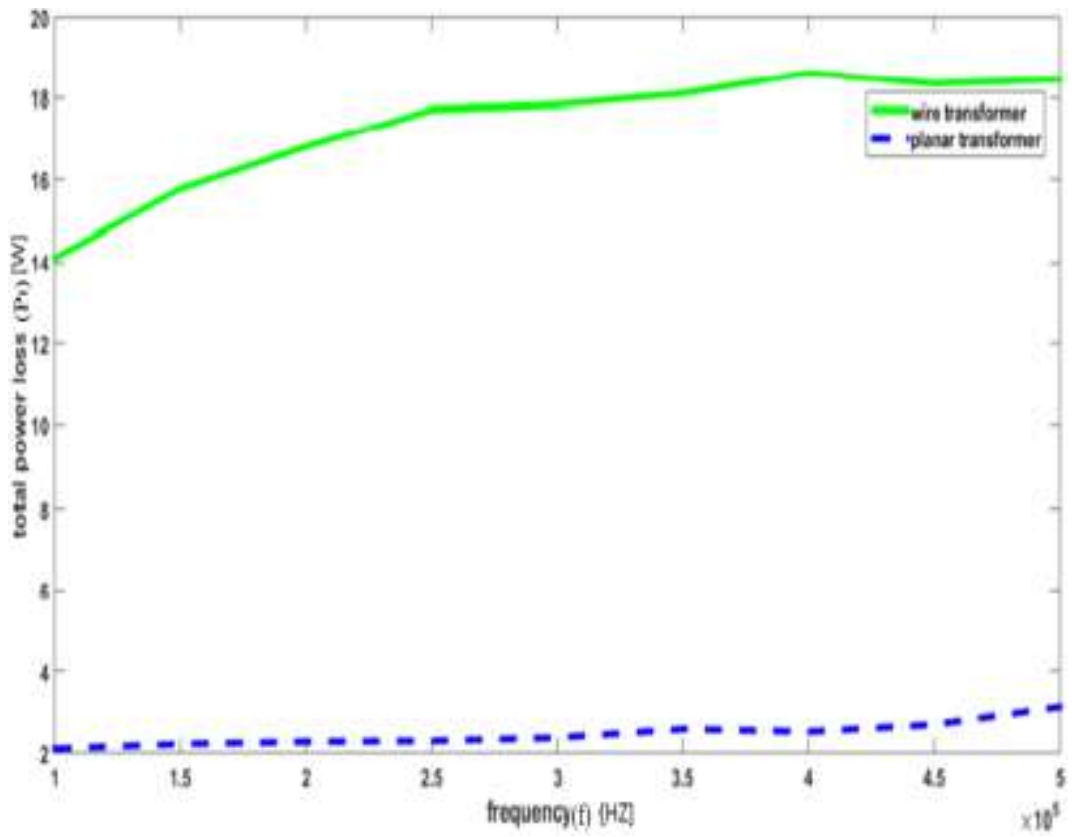

Fig. 9 relationship between total power loss with frequency in planar transformer and wire wound transformer. 
In Fig. 9, total power loss in planar transformer is less than total power loss in wire wound transformer so the efficiency of planar transformer is better than wire wound transformer. High power conversion efficiency more than $90 \%$ has been achieved for wide output voltage regulation ranges.

\section{MAGNETIZING INDUCTANCE OF PLANAR TRANSFORMER}

It can be classified as a transformer; various parasite elements have a major impact on its efficiency. Those elements are inductance of leakage, the capacitance of parasites, and resistance to the touch. This paper aims to provide thorough analyses of each item. The analysis incurs all the necessary equations and results from the discussion which helps to measure each parasite factor.

\subsection{Leakage inductance}

There's no question that, as opposed to an ideal version, a high-frequency transformer includes a variety of parasitic elements that can cause the power system to function abnormally. Some amount of these parasitic elements is needed, however, in some cases. One of those elements is the inductance of leakage. The correct selection of the inductance of leakage can help avoid higher switching losses and achieve zero-voltage switching conditions.

In addition to the main flux flowing through the core, there is also a leakage flux in a transformer that escapes from the core and flows through only one winding. This results in an additional inductance with the main and secondary windings appearing to be in order. It is called inductance leakage. The total sum of leakage and magnetizing inductivities reflects the transformer's self-inductance.

The inductance of the leakage is a parasitic element in the transformer and energy stored in the inductance of the leakage may produce voltage spikes [29, 40-45]. Spikes increase the switching losses and decrease the efficiency of the transformer. The leakage inductance of the planar transformer can be calculated by [30][45]:

$$
L_{k P l a n a r}=\frac{\mu_{o} l_{w} N_{p}^{2}}{b_{w} M^{2}} \times\left(\frac{\sum X_{\Delta}}{3}+\sum X_{\Delta}\right)
$$

where $L_{\text {kPlanar }}$ is the inductance of leakage, $\mu_{o}$ is the permeability of free space, $l_{w}$ is the length of one turn, $b_{w}$ is the width of the turn, $N_{p}$ is the number of turns, $\Sigma x$ is the sum of all section layer heights (windings), $\Sigma x_{\Delta}$ is the sum of the distances between layers (insulation, air), $M$ is the number of insulation layers. In the DAB converter, different values of leakage inductance may be required to achieve ZVS, depending on the operating frequency. As a result, the inductance of leakage is sometimes required to decrease or increase. In a transformer there are many methods by which it can be done:

- select the core that encloses the windings

- The primary and secondary windings interleave

- The difference between the primary and secondary windings changes

\subsection{Magnetizing inductance}

The magnetizing inductance $L_{m}$ is connected to the flux which links to the transformer's core compared with the leakage inductance. The magnetizing inductance can be calculated using following equation:

$$
L_{m}=\frac{A_{L} \times N^{2}}{1000}
$$

where $N$ is the number of turns, $A_{L}$ is an inductance factor value that the supplier has obtained and typically given in the datasheet. In the high-frequency transformer, there are many methods to change the magnetizing inductance:

- Vary the number of turns

- change an air-gap to the core

From these Eqs. (17) and (18) self-inductance can be calculated by:

$$
L=L_{m}+L_{K}
$$

\section{SWITCH MODE POWER SUPPLY USING PLANAR TRANSFORMER}

In this paper, we studied of using planar transformer in switch mode power supply in computer. Table 2 compares between the planar and wire-wound transformer when using them in computer power supply. 
TABLE 2 SPECIFICATIONS OF PLANAR AND WIRE-WOUND TRANSFORMER.

\begin{tabular}{c|c|c}
\hline Item & Planar & Wire-wound \\
\hline Size $(L \times W \times H) I$ in mm & $30 \times 26 \times 17$ & $35 \times 30 \times 30$ \\
\hline Weight & $0.2 \mathrm{~kg}$ & $0.34 \mathrm{~kg}$ \\
\hline Price & $10 €$ & $0.5 €$ \\
\hline Core material & \multicolumn{2}{|c}{ Ferrite } \\
\hline Core configuration & Planar E & EE
\end{tabular}

The voltage of winding and core-flux waveform created through one of switch mode power supply 'common topologies use an H-bridge converter to achieve the high-frequency AC voltage from input DC. The key feature of the switch mode power supply transformer is attached to the Input H-bridge. Then secondary lateral voltage is corrected then filtered to the desired magnitude of regulated DC output voltage. The windings of the transformer bear bidirectional current and the flux linking the windings is likewise Bipolar. Bipolar. The voltage for the input $\mathrm{DC}$ bus is unregulated and varies across a wide spectrum. The ' $\mathrm{D}$ ' duty-ratio within $D_{\min }<D<D_{\max }$ switches are regulated to regulate voltage performance. The secondary side voltage rectified by saying, in a steady state even after voltage fall accounting in the diode rectifier and filter inducer, the equals charge voltage required and can be presumed to be set to the tension production Yo. Under complex conditions therefore, that can occur because of sudden load or supply changes voltage, mean voltage (DC) at the secondary output side can be considerably higher than its permanent state Größe [12][45]. For peak flux determined in its root, the worst condition corresponds to the maximum task ratio $(D=0.95)$ with max of the voltage at input. The worst-case current $\left(I_{i}\right)$ through the windings corresponds to the average duty ratio $(D=0.95)$ and peak output (load) current $\left(I_{o}\right)$ magnitude.

\section{CONCLUSIONS}

In this paper, an overview of high-frequency transformer topologies was given, and a new transformer structure, was introduced. Diverse magnetic core shapes and types of winding were discussed an improved prototype of the high-frequency transformer connected FB type soft-switching PS-PWM power converter was proposed for low-voltage / large-current secondary-side or large-voltage / low-current applications such as plasma display panels, fuel cell generation systems, AC power supply systems, and power plants for telecommunications. Two newly specially designed high-frequency transformers are used at a high switching frequency of $100 \mathrm{kHz}$. On the basis of experimental results, the operating voltage and current waveforms are defined and discussed. All semiconductor switching devices can effectively perform ZVS on the primary side and ZCS on the secondary side. High power conversion efficiency more than $90 \%$ has been achieved for wide output voltage regulation ranges and widely load variations from full power to low power settings as compared with reduced efficiency converter proposed previously by the authors. It was also noted that the parasite capacity and the inductance of leakage are mutually dependent and decreasing one parameter results in an increase of one parameter. Detailed information was given about the centre and winding losses. Different winding and core loss determination approaches were addressed, and an optimal solution was found for each loss form. Besides, the chapter also discusses ways to calculate core and winding losses. Finally, all the necessary equations were provided for the transformer design. For low-voltage/large-current supply-side or large-voltage/low-current secondary-side applications such as plasma display panels, fuel cell power generation systems, automotive AC power supply systems and telecommunications power plants, an improved prototype of high-frequency transformer linked fullbridge PS-PWM DC-DC converter has been proposed.

\section{References}

[1] Khairy Sayed, Ahmed G. Abo-Khalil, and Ali S. Alghamdi, "Optimum Resilient Operation and Control DC Microgrid Based Electric Vehicles Charging Station Powered by Renewable Energy Sources," Energies 2019, 12, 4240; doi: 10.3390/en12224240.

[2] Khairy Sayed, "ZVS Soft-Switched DC-DC Converter based Charger for Low Voltage battery in Hybrid Electric Vehicles," IET Power Electronics, Vol. 12, pp. 3389-3396, 2019.

[3] Khairy Sayed, Keiki Morimoto, Soon-Kurl Kwon, Katsumi Nishida, Mutsuo Nakaoka, "DC-DC Converter with ThreePhase Power Factor Correction for Arc Welder," Power Electronics and ECCE Asia (ICPE \& ECCE), 2011 IEEE 8th International Conference on, pp. 1273 - 1277, 2011.

[4] M.T. Quirke, J.J. Barrett, and M. Hayes, "Planar magnetic component technology-a review," IEEE Transactions on Components, Hybrids, and Manufacturing Technology, 1992. 15(5): pp. 884 - 92.

[5] C. Quinn, K. Rinne, T. O’Donnell, M. Duffy, and C.O. Mathuna, "A review of planar magnetic techniques and technologies," in 16th Annual IEEE Applied Power Electronics Conference and Exposition. 2001. Anaheim, CA, USA: IEEE. 
[6] André Büttner, Arne Nysveen and Magnar Hernes, "High frequency winding design for planar switch mode transformers," in: NORPIE/2008 Nordiac Workshop on Power and Industrial Electronics, Espoo, Finland, June 9-11, 2008.

[7] Ferroxcube, "Design of planar power transformers" Application Note 2001.

[8] W. Chen, Y. Yan, Y. Hu, and Q. Lu, "Model and design of PCB parallel winding for planar transformer," IEEE Transactions on Magnetics, vol. 39 nr. 5, pp. 3202-3204, September 2003.

[9] M. N. Kheraluwala, R. W. Gascoigne, D. M. Divan and E. D. Baumann, "Performance characterization of a high-power dual active bridge DC-to-DC converter," IEEE Transactions on Industry Applications, vol. 28, no. 6, pp. 1294-1301, Nov/Dec 1992.

[10] Khairy F. Sayed, Keiki Morimoto, Soon Kurl Kwon and Mutsuo Nakaoka, "A New High Frequency Linked Half-Bridge Soft-Switching PWM DC-DC Converter with Input DC Rail Side Active Edge Resonant Snubbers," IET Power Electronics, Vol. 3, No. 5, pp. 774-783, 2010..

[11] Khairy Sayed, Keiki Morimoto, Soon-Kurl Kwon, Katsumi Nishida, Mutsuo Nakaoka, "New DC Rail Side SoftSwitching PWM DC-DC Converter with High Frequency Planar Transformer," Power Electronics and ECCE Asia (ICPE \& ECCE), 2011 IEEE 8th International Conference on, pp: 44 - 51, 2011.

[12] Khairy Sayed, Keiki Morimoto, Soon-Kurl Kwon, Katsumi Nishida, Mutsuo Nakaoka, "DC-DC Converter with ThreePhase Power Factor Correction for Arc Welder," Power Electronics and ECCE Asia (ICPE \& ECCE), 2011 IEEE 8th International Conference on, pp. 1273 - 1277, 2011.

[13] Khairy Sayed and Hossam A. Gabbar, "Electric Vehicle to Power Grid Integration Using Three-Phase Three-Level AC/DC Converter and PI-Fuzzy Controller,” Energies, Vol. 9, No. 7, p. 532, 2016.

[14] Khairy Sayed, and Mutsuo Nakaoka, "Performance of Induction Heating Power Supply Using Dual Control Mode PWMPDM High Frequency Inverter," Journal of Electrical Power Components and Systems, Vol. 43, No. 2, pp. 1-10, 2015.

[15] G. Guidi et. al, "Efficiency optimization of high power density Dual Active Bridge DC-DC converter," 2010 Int. Power Electron. Conf. - ECCE ASIA -, no. 1, pp. 981-986, 2010.

[16] M. Mu et. al, "Design of integrated transformer and inductor for high frequency dual active bridge GaN Charger for PHEV," 2015 IEEE Applied Power Electronics Conference and Exposition (APEC) 2015, pp. 579-585.

[17] F. M. Ni and T. L. Lee, ,'Implementation of a directional three-phase dual-active-bridge DC converter with hybrid modulation for electric vehicle applications," 2014 International Conference on Intelligent Green Building and Smart Grid (IGBSG), Taipei, 2014, pp. 1-4.

[18] V. Cekov Valchev and A. Van denBossche, Inductors and Transformers for Power Electronics. Boca Raton, FL: CRC Press, 2005, ch.1.

[19] Fu Wong and Junwei Lu, "High frequency planar transformer with helical winding structure," IEEE Transactions on Magnetics, Vol. 36, No. 5, pp. 3524-3526, Sep 2000.

[20] O. Oshiro, H. Tsujimoto and K. Shirae, "Structures and Characteristics of Planar Transformers," IEEE Translation Journal on Magnetics in Japan, Vol. 4, No. 5, pp. 332-338, May 1989.

[21] Epcos Corp., Ferrite and accessories. [Online]. Avaiable: http://www.epcos.com

[22] R.Erickson, Fundamentals of Power Electronics. Second Edition. Secaucus, NJ, USA: Kluwer Academic Publishers, 2000. p.571

[23] N.Mohan, T.M. Undeland, and W.P.Robbins, Power electronics - Converters, Applications and Design 2nd ed., New York: John Wiley \& Sons Inc.,1995,ch.30

[24] Magnetics inc. Ferrite catalogue, 2017.

[25] Boglietti A, Cavagnino A, Lazzari M, et al. "Predicting iron losses in soft magnetic materials with arbitrary voltage supply: an engineering approach,” IEEE Trans. Magn., Vol. 39, No. 2, pp.981-989, March 2003.

[26] Bertotti G. "General properties of power losses in soft ferromagnetic materials," IEEE Trans. Magn., Vol. 24, No. 1, pp. 621-630, January, 1988.

[27] S. Wang, M. A. de Rooij, W. G. Odendaal, J. D. van Wyk, and D. Boroyevich, "Reduction of High-Frequency Conduction Losses Using a Planar Litz Structure," in IEEE Transactions on power electronics, Vol. 20, No. 2, pp 261-267, March 2005.

[28] Khairy Sayed, ,"A High Efficiency DC-DC Converter with LC Resonant in the Load-Side of HFT and Voltage Doubler for Solar PV Systems,” International Journal of Power Electronics, Vol. 8, No. 3, pp. 232-248, 2017.

[29] Colonel Wm. T. McLyman, "Transformer and Inductor Design Handbook”, 2nd Ed., Marcel Dekker, 1988.

[30] M. Mu et. al, "Design of integrated transformer and inductor for high frequency dual active bridge GaN Charger for PHEV,"2015 IEEE Applied Power Electronics Conference and Exposition (APEC), 2015, pp. 579-585.

[31] A Almutairi, K Sayed, N Albagami, AG Abo-Khalil, H Saleeb, "Multi-Port PWM DC-DC Power Converter for Renewable Energy Applications," Energies, Vol. 14, No. 12, p. 3490, 2021.

[32] K. Sayed, A. M. Kassem, I. Aboelhassan, A. M. Aly and A. G. Abo-Khalil, "Energy Management and Control Strategy of DC Microgrid Including Multiple Energy Storage Systems," 2019 21st International Middle East Power Systems Conference (MEPCON), 2019, pp. 736-741, doi: 10.1109/MEPCON47431.2019.9008076.

[33] H. A. Gabbar and K. Sayed, "Smart distribution system Volt/VAR control using the intelligence of smart transformer," 2016 IEEE Smart Energy Grid Engineering (SEGE), 2016, pp. 52-56, doi: 10.1109/SEGE.2016.7589499.

[34] Jose P. Therattil; Jenson Jose; Praveen Raveendran Nair Prasannakumari; Ahmed G. Abo-khalil; Ali S. Alghamdi; Bindu Gopakumar Rajalekshmi; Khairy Sayed, "Hybrid control of a multi-area multi-machine power system with FACTS devices using non-linear modelling," Vol. 14, No. 10, pp. 1993 - 200322, May 2020.

[35] Sayed, K.; Abo-Khalil, A.G.; S. Alghamdi, A. "Optimum Resilient Operation and Control DC Microgrid Based Electric Vehicles Charging Station Powered by Renewable Energy Sources," Energies 2019, Vol. 12, p. 4240. https://doi.org/10.3390/en12224240

[36] Almutairi, A.; Abo-Khalil, A.G.; Sayed, K.; Albagami, N. "MPPT for a PV Grid-Connected System to Improve Efficiency under Partial Shading Conditions," Sustainability 2020, Vol. 12, p. 10310. https://doi.org/10.3390/su122410310.

[37] Ahmed G. Abo-Khalil and Khairy Sayed, "Wind Turbine Simulation and Control Using Squirrel-Cage Induction Generator for DFIG Wind Energy Conversion Systems," Sohag Engineering Journal (SEJ), Vol. 1, No. 1, March 2021.

[38] Khairy Sayed and Ahmed M. Kassem, "Sensorless Vector Controlled Three-Phase PWM Inverter-Fed Induction Motor Drive System with Auto-Tuning Estimation of Machine Parameter Approach," Sohag Engineering Journal (SEJ), Vol. 1, No. 1, March 2021. 
[39] Almutairi, A.; Abo-Khalil, A.G.; Sayed, K.; Albagami, N. "MPPT for a PV Grid-Connected System to Improve Efficiency under Partial Shading Conditions," Sustainability 2020, Vol. 12, p. 10310. https://doi.org/10.3390/su122410310.

[40] Sayed, K.; Kassem, A.; Saleeb, H.; Alghamdi, A.S.; Abo-Khalil, A.G. "Energy-Saving of Battery Electric Vehicle Powertrain and Efficiency Improvement during Different Standard Driving Cycles," Sustainability 2020, Vol. 12, p. 10466. https://doi.org/10.3390/su122410466.

[41] Sayed, K.; Ali, Z.M.; Aldhaifallah, M. "Phase-Shift PWM-Controlled DC-DC Converter with Secondary-Side Current Doubler Rectifier for On-Board Charger Application,” Energies 2020, Vol. 13, p. 2298. https://doi.org/10.3390/en13092298

[42] Eltamaly, A.M.; Al-Saud, M.; Sayed, K.; Abo-Khalil, A.G. "Sensorless Active and Reactive Control for DFIG Wind Turbines Using Opposition-Based Learning Technique," Sustainability 2020, Vol. 12, p. 3583. https://doi.org/10.3390/su12093583

[43] Sayed, K.; Gronfula, M.G.; Ziedan, H.A. "Novel Soft-Switching Integrated Boost DC-DC Converter for PV Power System," Energies 2020, Vol. 13, p. 749. https://doi.org/10.3390/en13030749

[44] Abo-Khalil, A.G.; Alyami, S.; Sayed, K.; Alhejji, A. Dynamic Modeling of Wind Turbines Based on Estimated Wind Speed under Turbulent Conditions. Energies 2019, Vol. 12, p. 1907. https://doi.org/10.3390/en12101907

[45] Abo-Khalil, A.G.; Alghamdi, A.S.; Eltamaly, A.M.; Al-Saud, M.S.; R. P., P.; Sayed, K.; Bindu, G.R.; Tlili, I. "Design of State Feedback Current Controller for Fast Synchronization of DFIG in Wind Power Generation Systems," Energies 2019, Vol. 12, p. 2427. https://doi.org/10.3390/en12122427 